\title{
Corrigendum
}

\section{Corrigendum to "Concise Robust Control of Marine Engine Speed Based on Backstepping and Its Fuzzy Comprehension"}

\author{
Lijun Wang ${ }^{1,2}$ and Sisi Wang $\mathbb{D}^{1}$ \\ ${ }^{1}$ School of Navigation, Guangdong Ocean University, Zhanjiang 524088, China \\ ${ }^{2}$ Hubei Key Laboratory of Inland Shipping Technology, Wuhan 430063, China \\ Correspondence should be addressed to Sisi Wang; mars32lin@sina.com \\ Received 24 March 2020; Accepted 25 March 2020; Published 27 April 2020 \\ Copyright (C) 2020 Lijun Wang and Sisi Wang. This is an open access article distributed under the Creative Commons Attribution \\ License, which permits unrestricted use, distribution, and reproduction in any medium, provided the original work is \\ properly cited.
}

In the paper "Concise Robust Control of Marine Engine Speed Based on Backstepping and Its Fuzzy Comprehension" [1], the authors' order is corrected as above.

\section{References}

[1] L. Wang and S. Wang, "Concise robust control of marine engine speed based on backstepping and its fuzzy comprehension," Complexity, vol. 2019, Article ID 5823827, 7 pages, 2019. 